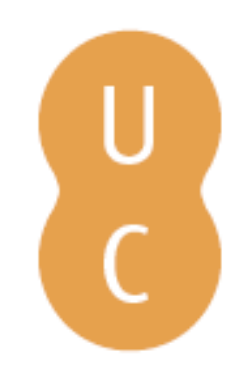

\title{
pompalina
}

\section{Variabilidade como método de treino}

Autor(es): $\quad \begin{aligned} & \text { Mendes, Pedro Cabral; Fuentes, Juan Pedro; Menayo, Ruperto; Dias, } \\ & \text { Gonçalo }\end{aligned}$

Publicado por: Imprensa da Universidade de Coimbra

URL

persistente: URI:http://hdl.handle.net/10316.2/41768

DOI: $\quad$ DOI:https://doi.org/10.14195/978-989-26-1286-7_7

Accessed : $\quad$ 26-Apr-2023 11:40:47

A navegação consulta e descarregamento dos títulos inseridos nas Bibliotecas Digitais UC Digitalis, UC Pombalina e UC Impactum, pressupõem a aceitação plena e sem reservas dos Termos e Condições de Uso destas Bibliotecas Digitais, disponíveis em https://digitalis.uc.pt/pt-pt/termos.

Conforme exposto nos referidos Termos e Condições de Uso, o descarregamento de títulos de acesso restrito requer uma licença válida de autorização devendo o utilizador aceder ao(s) documento(s) a partir de um endereço de IP da instituição detentora da supramencionada licença.

Ao utilizador é apenas permitido o descarregamento para uso pessoal, pelo que o emprego do(s) título(s) descarregado(s) para outro fim, designadamente comercial, carece de autorização do respetivo autor ou editor da obra.

Na medida em que todas as obras da UC Digitalis se encontram protegidas pelo Código do Direito de Autor e Direitos Conexos e demais legislação aplicável, toda a cópia, parcial ou total, deste documento, nos casos em que é legalmente admitida, deverá conter ou fazer-se acompanhar por este aviso.

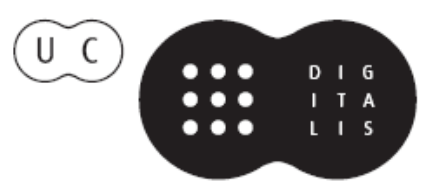


IMPRENSA DA UNIVERSIDADE DE COIMBRA

COIMBRA UNIVERSITY PRESS

RAUL A.

MARTINS

GONÇALO DIAS

PEDRO CABRAL MENDES

\section{EDITORES}

ESTRATÉGIA

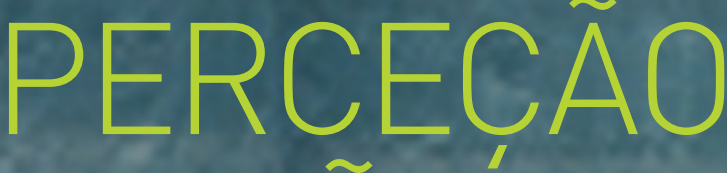

EAGÃA

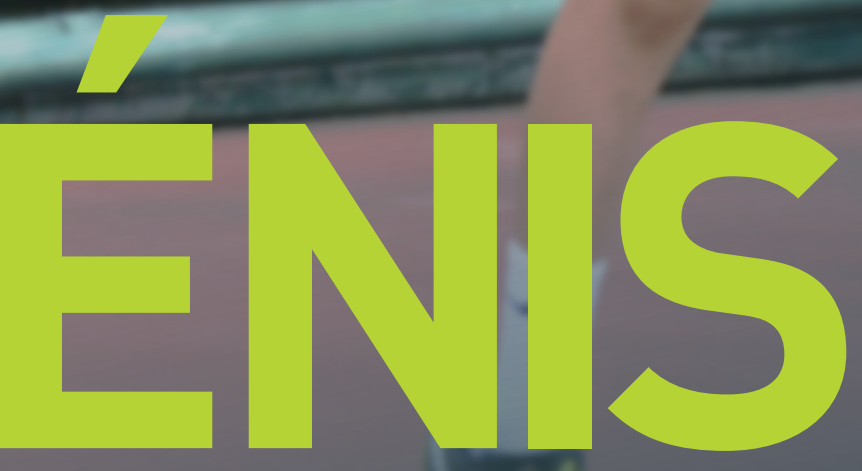




\title{
CAPÍTULO 7 \\ VARIABILIDADE COMO MÉTODO DE TREINO
}

\author{
Pedro Cabral Mendes \\ Juan Pedro Fuentes \\ Ruperto Menayo \\ Gonçalo Dias
}

\section{Introdução}

A variabilidade é uma característica intrínseca aos sistemas de movimento humano, onde a repetição de uma determinada tarefa motora emerge como um ato único e irrepetível (Bernstein, 1967; Latash e col., 2002). Atualmente esta perspetiva não é entendida como uma limitação por parte dos investigadores, mas antes como uma oportunidade para melhor compreender a dinâmica de ação do comportamento motor humano (Riley \& Turvey, 2002). Além disso, a variabilidade presente no sistema motor constrange os praticantes a adaptarem-se perante diferentes constrangimentos, nomeadamente orgânicos ou do próprio atleta, da tarefa e de envolvimento (Newell, 1986).

O estudo sobre a variabilidade motora que está patente na área do Controlo Motor enaltece a relevância dos processos adaptativos e de autorganização que operam no aprendiz ou perito, incidindo o seu escopo na procura de respostas objetivas sobre este fenómeno. Neste seguimento, a variabilidade é entendida como parte 
integrante, omnipresente e inevitável no comportamento motor (Davids e col., 2003).

$\mathrm{O}$ referencial teórico indicado anteriormente, tem angariado relevância e aceitação junto de diversos investigadores que estudam movimentos e gestos técnicos associados ao Ténis (Araújo \& Carvalho, 2007; Elliott e col., 2009; Menayo, 2010; Hernández-Davó e col., 2014), os quais procuram articular a produção de conhecimento e a sua desejável aplicabilidade no terreno, i.e., no treino desportivo e competição. Sobre este propósito, Girard e colegas (2007), analisaram a cinemática do primeiro serviço de ténis, constrangendo o ângulo de flexão dos joelhos, sendo que Menayo (2010) variou o tipo e tamanho de raquete e bola. Whiteside e colaboradores (2014), analisaram a coordenação na rotação das articulações dos membros inferiores, tronco, braço-raquete e a localização da bola na execução do serviço de ténis, e observaram diferenças na variabilidade e consistência no movimento destes segmentos corporais e no impacto da bola, entre tenistas de elite, pré-púberes, púberes e mulheres adultas. Contrariamente aos constrangimentos de tarefa descritos, os de natureza ambiental são de difícil manipulação, quer seja por parte do investigador ou do treinador (Newell, 1986). Ainda assim, não obstante esta dificuldade de cariz experimental em estudar os fatores extrínsecos ao praticante, as mudanças ambientais provocam adaptações no executante que são importantes no contexto da performance (Davids e col., 2008; Elliott e col., 2009). Posto isto, e tendo como pano de fundo as ações técnicas fundamentais do ténis, iremos contextualizar de seguida algumas questões que retratam a importância da variabilidade no processo de treino.

\section{Será possível realizar dois movimentos exatamente iguais?}

$\mathrm{Na}$ prática, o ser humano é incapaz de realizar dois movimentos exatamente iguais (Bernstein, 1967). Mesmo tenistas de elite 
não reproduzem padrões de movimento idênticos, sejam eles mais estáveis como o serviço (tarefa fechada) ou mais adaptáveis às circunstâncias do próprio jogo como são os golpes de fundo (direita e esquerda), apesar dos anos de prática a que foram submetidos (Davids e col., 2003; Schöllhorn, 1999). Isto deve-se à variabilidade do movimento humano que é intrínseca ao perfil morfológico e funcional de cada praticante (Newell \& Corcos, 1993). Ao estudar-se os parâmetros determinantes num determinado movimento (e.g., momento de força, momentos angulares, velocidade de aceleração, posição, entre outros), observar-se-á que estes podem aproximar-se em diferentes ensaios de prática motora, mas nunca serão totalmente idênticos. Conforme foi descrito anteriormente, o sistema motor responsável pela execução do movimento, apresenta um número elevado de graus de liberdade, materializáveis nas muitas articulações e respetivos músculos que viabilizam a ocorrência de ações singulares (Kudo \& Ohtsuki, 2008).

\section{Será o ténis igual a modalidades como a ginástica ou o tiro ao alvo?}

O ténis é considerado por diferentes autores como uma modalidade desportiva que apresenta uma estrutura funcional diferenciadora de outros desportos (e.g., Castejón, 1995; Parlebas, 1981). Deste modo, e de acordo com a literatura especializada em taxonomias de classificação dos desportos, autores como Knapp (1979), Parlebas (1994) e Hernández (2005) classificam o ténis segundo o critério da continuidade ou do incremento da complexidade estrutural da tarefa desportiva. Neste seguimento, considerando que o repertório técnico no ténis é predominantemente composto por habilidades de "natureza aberta", exige do praticante um contínuo ajuste espaciotemporal. Complementarmente, a ação do jogador acaba por ser 
influenciada pelo opositor no caso do jogo de singulares, e pelo companheiro e dupla de oponentes no jogo de pares. Face ao descrito, a complexidade que está subjacente à tomada de decisão do tenista, pressupõe uma adaptação constante associada ao conceito de variabilidade. Neste sentido, Hernández (1994), com base na classificação de Parlebas (1981) e de Blázquez e Hernández (1984), caracteriza o ténis como um desporto de oposição e, mais concretamente, de espaço separado e participação alternativa. Na mesma linha de pensamento, Castejón (1995) define-o como um desporto de adversário. Todas as anteriores características implicam uma interação antagonista de contra-comunicação (Gorospe, 2005).

Conforme o descrito relativamente à caracterização do ténis como desporto, o processo de treino deve respeitar a lógica interna da modalidade, proporcionando ao praticante tarefas que sejam representativas do jogo. Dito de outro modo, os constrangimentos na tarefa (Menayo, 2010) e ambientais (Mendes, 2012) devem ser integrados na preparação desportiva dos tenistas de forma multilateral, tendo sempre em conta as capacidades psicomotoras dos atletas e o seu grau de motivação para o desempenho da tarefa.

\section{A variabilidade será necessária para o ensino e treino do ténis?}

Ao entendimento da variabilidade como algo pouco adequado à aprendizagem, conforme sustentam Adams (1971) e Schmidt (1975) e que corporizam as teorias cognitivistas, a perspetiva dinâmica contrapõe, atribuindo à variabilidade um papel importante no estabelecimento de novos padrões coordenativos (Bartlett e col., 2007; Hamill e col., 2006; Riley \& Turvey, 2002). Ainda sobre este tema, Glazier e Davids (2009) consideram que a variabilidade no comportamento motor deve ser encarada como o resultado das adaptações 
individuais aos constrangimentos intrínsecos e extrínsecos ao organismo, percetíveis no tenista quando se adapta a condições climatéricas desfavoráveis, se depara com um público hostil, ou responde adequadamente a estados de fadiga elevados, entre outros fatores.

$O$ facto de um atleta não executar dois movimentos exatamente iguais, não significa que não possa ser estável na sua prestação motora. Graças a este aparente paradoxo, o sistema motor é flexível e adaptável, conciliando as flutuações com a própria estabilidade no desempenho motor (Davids e col., 2005; Tani, 1998; Tani, 2005).

Um outro problema, que é complementar ao exposto anteriormente, prende-se com a capacidade do sistema motor alcançar o mesmo resultado mas com uma considerável variação nos componentes individuais, ou seja, a "abundância" motora (i.e., graus de liberdade) do sistema motor acaba por proporcionar rendimentos estáveis. Neste sentido, Hughes (1976) designou-o por equivalência motora e tem merecido destaque junto de diversos investigadores da área do controlo motor (Davids e col., 2003; Tani, 1998; Kudo \& Ottsuki, 2008). Nesta ótica, um jogador experiente caracteriza-se por realizar um determinado golpe procurando manter estáveis determinadas características invariantes, como sejam o ritmo do movimento (i.e., a preparação mais lenta e a fase de aceleração muito rápida), ou o equilíbrio do corpo no momento do impacto com a bola, em qualquer momento do jogo, entre outras variáveis.

No seguimento desta abordagem dinâmica à variabilidade motora, o ruído (i.e., flutuações aleatórias) pode desempenhar um importante papel ao prevenir que o sistema se torne demasiado estável em contextos de envolvimento complexos, permitindo, assim, a emergência de soluções motoras funcionais durante comportamentos exploratórios de atletas aquando da prática motora. Entenda-se, neste contexto, por ruído, todo o tipo de "perturbações" intrínsecas e extrínsecas capazes de desencadear nos praticantes mecanismos de autorganização da ação motora. No caso concreto do ténis, 
o treinador, ao aumentar, por exemplo, a altura da rede, potencia no jogador a procura de soluções motoras que superem este constrangimento de tarefa. Esta característica funcional do sistema motor é percetível em atletas peritos, quando libertam ou "congelam" os graus de liberdade de uma cadeia de movimento em função das exigências dos estímulos presentes no envolvimento (Davids e col., 2003; Newell \& Villancourt, 2001). Deste modo, os praticantes peritos em contextos de prática motora de natureza complexa, conseguem modelar os seus movimentos com base nas informações percetivas existentes no meio (Davids e col., 1999). Nesta ótica, a literatura designa de variabilidade compensatória esta funcionalidade da variabilidade do sistema dos movimentos humanos (Davids e col., 2008).

Os precursores na análise da variabilidade compensatória, concretamente Arutyunyan e colaboradores (1968), identificaram diferentes níveis de variabilidade no membro superior em desportistas peritos no tiro com pistola. Posteriormente, Scholz e colaboradores (2000) deram continuidade a esta linha de investigação em outros desportos. No essencial, estes autores observaram elevados níveis de variabilidade nas articulações do ombro e do cotovelo e um comportamento mais estável no punho que segurava a pistola. Contudo, este comportamento não se verificou em atiradores principiantes, onde apresentaram um comportamento instável na articulação mais distal.

Por seu lado, o estudo realizado por Bootsma e Van Wieringen (1990) com jogadores de ténis de mesa, mostra que o decréscimo da variabilidade no ponto de impacto da bola com a raquete no movimento de direta induziu comportamentos compensatórios no momento do início do movimento.

Mais recentemente, Davids e colegas (1999, 2006), analisaram o serviço por cima com jogadores de voleibol e constataram que a invariante do lançamento da bola, na sua dimensão vertical, era compensada através de uma maior variabilidade nas dimensões lateral e profundidade. Nesta linha de pensamento, Handford (2006) 
ao comparar lançamentos sem contacto na bola com lançamentos com contacto no serviço de voleibol, verificou uma maior consistência nas dimensões lateral e profundidade, assim como uma menor consistência na dimensão vertical na condição de prática sem batimento. Segundo o mesmo autor (2006), separar o lançamento da fase do batimento, possivelmente, não tem um transfer positivo para o serviço (i.e., movimento global), uma vez que não salvaguarda a dinâmica coordenativa e as relações perceção-ação chave que dão "identidade" ao movimento.

Relativamente ao ténis, destaca-se o estudo realizado por Douvis (2005) sobre a prática variável na aprendizagem do movimento de direita em principiantes sem experiencia prévia em qualquer desporto de raquete: crianças com 9-10 anos de idade e jovens estudantes com 18-19 anos de idade. Neste trabalho, desenhou-se um programa de intervenção baseado na prática variável de 18 sessões distribudas por 40 dias, onde os praticantes deveriam realizar movimentos de direita, sempre do mesmo lugar. Delimitou-se com cones do lado contrário do court atrás da linha de serviço e em diferentes profundidades, cinco alvos. Durante a prática, os participantes deveriam realizar os movimentos de direita, tendo por base os referidos alvos: o primeiro grupo procurou direcionar a bola sempre para o mesmo alvo; o segundo grupo teve quatro alvos diferentes; o terceiro grupo teve cinco alvos e; um quarto grupo sem nenhum alvo concreto, ou seja, enviar a bola por cima da rede e dentro dos limites do lado court contrário. As crianças e jovens estudantes foram divididos no total em oito grupos iguais de acordo com a idade e no grupo de treino. Os resultados refletiram maiores benefícios a partir da prática variável, especialmente em crianças, nos grupos que praticavam com quatro ou cinco alvos comparativamente com os praticantes dos grupos sem um alvo concreto ou com apenas um alvo específico.

Em linha com o descrito, Hernández-Davo e colaboradores (2014) levaram a cabo uma investigação com o objetivo de analisar os efeitos 
da prática da variabilidade na melhoria de uma habilidade fechada no ténis, o serviço. Assim, trinta jovens tenistas (20 homens e 10 mulheres) de $13 \pm 1,52$ anos de idade participaram no estudo. Um grupo praticou em condições variáveis e o outro em condições de consistência (prática constante). Ambos os grupos realizaram 12 sessões de treino (60 serviços/sessão), fazendo com que o grupo de prática variável obtivesse uma melhoria significativa na precisão em comparação com o outro grupo. Por seu lado, ambos os grupos aumentaram a velocidade do serviço. Os autores concluíram que houve eficácia do treino em prática variável para a melhoria do ténis no ténis.

Por sua vez, o estudo realizado por Reid e colegas (2010), que analisou cinco tenistas juniores de elite, comparou o primeiro serviço com o lançamento da bola sem batimento e o movimento (swing) da raquete sem lançamento. As conclusões deste estudo mostram um decréscimo da consistência nas condições onde se decompôs o serviço, i.e., no lançamento e movimento da raquete isolados. Os referidos autores (2010) concluíram ainda que a decomposição do gesto, como é o caso da prática fracionada do lançamento da bola, altera significativamente as características dominantes do serviço. Mais ainda, os constrangimentos resultantes da setorização do serviço afastam-no significativamente da tarefa original ou padrão global, tornando-o num movimento diferente, menos dinâmico e complexo (Goodman \& Kelso, 1980).

Perante o exposto, e no caso específico do treino em habilidades do ténis, será aplicável a variabilidade, conforme é sugerida no contexto científico, e mais concretamente na área do controlo motor. Em linha com o descrito nas investigações aqui mencionadas, as mesmas extravasam a esfera científica e acabam por ter repercussões também no terreno (i.e., treino), corporizando a ideia da variabilidade motora como uma característica necessária e benéfica para alcançar o rendimento desportivo desejado (Elliot e col., 2009). 


\section{Modelo dos constrangimentos de Newell na variabilidade do processo de treino}

O Modelo de Newell (1986) para a realização de habilidades motoras estabelece um espaço funcional de relações entre os constrangimentos do organismo, do ambiente e da tarefa (Figura 1).

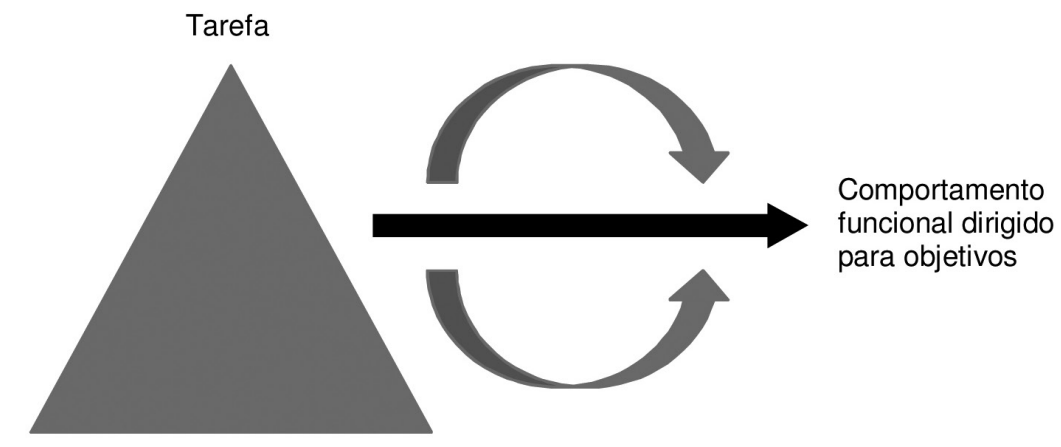

Ambiente

Desportista

Figura 1. Modelo de constrangimentos (Adaptado de Newell, 1986)

Entende-se, neste contexto, por constrangimento, um aspeto particular de organização (e.g., dimensões do campo, antropometria do jogador, perceção de determinada situação) que limita o espetro, dentro do qual podem surgir diferentes soluções para resolver um determinado problema motor. Os constrangimentos do organismo, do ambiente e da tarefa são indissociáveis da perspetiva de análise do praticante e objeto (Newell \& Ranganathan, 2010; Pellegrini, 2001). Importa assim clarificar que os constrangimentos são componentes do sistema que se ligam, não sendo elementos "opressores" ou "punidores" que de alguma maneira retiram a liberdade do sistema motor (Araújo, 2006).

Deste modo, constranger ações significa que existe um espaço delimitado dentro do qual todas as soluções são exequíveis, não sendo possíveis fora desse reduto (Araújo, 2005). No caso concreto do ténis e apesar do leque infinito de jogadas passíveis de realizar 
num campo de ténis, todas essas soluções de jogo são necessariamente constrangidas, entre outros aspetos, pelo utensílio de jogo (raquete), dimensões do campo e quadro regulamentar (Davids \& Araújo, 2005).

Por seu lado, os constrangimentos do praticante referem-se às características individuais dos jogadores, que tanto podem ser estruturais como funcionais. Sobre os constrangimentos estruturais, estes tendem a ser de natureza física e mantêm-se relativamente estáveis ao longo do tempo (e.g. estatura e composição corporal, número de graus de liberdade mecânicos e a distribuição do tipo de fibras musculares). Relativamente aos constrangimentos funcionais, verifica-se que estes são potencialmente mais variáveis com o tempo e tanto podem ser físicos como psicológicos. Exemplos destes constrangimentos são as intenções, emoções, perceção, e a tomada de decisão (Glazier \& Davids, 2009).

A partir do momento em que se estabelece um padrão de coordenação funcional para a concretização da tarefa, este padrão vai sendo aperfeiçoado pelo praticante, em virtude da descoberta das variações dos constrangimentos informacionais de diferentes contextos de desempenho. Retomando o exemplo anterior, um tenista quando confrontado com diferentes tipos de trajetória e efeito da bola na execução de uma direita, pode adaptar os seus padrões de coordenação a essas fontes de informação disponíveis, em contexto de mudança, variando o padrão à medida que as circunstâncias mudam. No caso concreto dos peritos, estes podem explorar as forças disponíveis no seu envolvimento, para produzir uma solução económica e eficiente para dar resposta às situações em mudança em contextos dinâmicos (Davids \& Araújo, 2005; Araújo, 2006).

Os constrangimentos do ambiente podem ser físicos e socioculturais. Relativamente aos primeiros, o vento, a luz ambiente, a altitude, a chuva ou a temperatura podem afetar significativamente o funcionamento do movimento humano. Mais ainda, os 
constrangimentos de natureza sociocultural, como a família, os amigos, as expectativas sociais e o ambiente de treino, também podem condicionar o desempenho do praticante (Haywood \& Getchell, 2005). Finalmente, os constrangimentos da tarefa são categorizáveis em três tipos de componentes: 1) os objetivos; 2) o quadro regulamentar de um determinado desporto ou as condições específicas de uma tarefa em particular e; 3) os utensílios e engenhos usados no decorrer de uma prática.

Apresentam-se, de seguida, alguns estudos que recorreram ao constrangimento da tarefa em destrezas discretas. Neste contexto, Moreno e colegas (2011) analisaram a variabilidade e a exatidão do lançamento por cima com jovens andebolistas, perturbando-lhes as condições específicas da tarefa, ou seja, a realização do lançamento numa superfície instável (Bosu). Ainda neste âmbito, Girard e colaboradores (2007) estudaram o movimento do serviço, com e sem restrição da flexão dos membros inferiores. Sobre a última componente, alteração de utensílios ou engenhos necessários para a tarefa, Menayo (2010) analisou a variabilidade do serviço de ténis em jogadores de nível intermédio, variando o tamanho e o peso da raquete e da bola.

Posto isto, e para Newell (1986), os diferentes tipos de constrangimentos apresentados anteriormente interagem para influenciar o desempenho, ou seja, não atuam isoladamente. Nesse sentido, o comportamento motor como emerge da interação entre o praticante e o ambiente rumo ao objetivo da tarefa, não pode ser linearmente determinado por estas categorias fracionadas.

Ainda no âmbito do ténis, Elliott e colaboradores (2009) apresentam alguns exemplos de constrangimentos da tarefa, do praticante e de envolvimento como potenciadores de otimizar o desempenho (Tabela 1). Os referidos autores, consideram as perturbações na tarefa como sendo as que mais facilmente poderão ser manipuladas pelo treinador. 
Tabela 1. Categorias de constrangimentos aplicados ao ténis (adaptado de Elliott e col., 2009)

\begin{tabular}{|c|c|c|}
\hline Constrangimentos & Exemplos gerais & Exemplos práticos no Ténis \\
\hline Tarefa & $\begin{array}{l}\text { Condições ou regras } \\
\text { Dimensões do campo } \\
\text { Superfície } \\
\text { Equipamento }\end{array}$ & $\begin{array}{l}\text { Execução do slice de esquerda } \\
\text { sem apoio da mão não } \\
\text { dominante, colocando-a atrás } \\
\text { das costas. } \\
\text { Aumentar a altura da rede ou } \\
\text { servir } 2 \mathrm{~m} \text { atrás da linha de } \\
\text { fundo. } \\
\text { Jogar em piso rápido como se } \\
\text { se tratasse de terra batida. } \\
\text { Aumentar o swing nos gestos } \\
\text { de fundo. } \\
\text { Recurso a raquetes de menores } \\
\text { dimensões e aumento do } \\
\text { diâmetro da bola. }\end{array}$ \\
\hline
\end{tabular}

Antropometria (estatura, massa corporal, etc.)

Praticante Neurobiologia/ fisiologia (genes, rácio músculo - gordura) Comprimento da alavanca Diâmetro abdominal

Nível técnico corrente Treinabilidade

Envolvimento

Luminosidade

Temperatura

Vento
Jogar com luminosidade reduzida

Com vento ou sol

Relativamente às três dimensões de constrangimentos já descritas, Newell e Jordan (2007) propõem que os constrangimentos de envolvimento englobem qualquer constrangimento físico que seja extrínseco ao organismo do indivíduo. Deste modo, os instrumentos e dispositivos originalmente categorizados por Newell (1986) de constrangimentos de tarefa, são agora reconsiderados pelo mesmo como constrangimentos de envolvimento. Neste contexto, Newell e Ranganthan (2010) reforçam ainda que os objetivos da tarefa e os constrangimentos relacionados com o movimento definem a fronteira na interação do indivíduo com o envolvimento aquando da realização de uma ação motora. 


\section{Como dosear a carga de variabilidade no processo de treino?}

Estudos recentes analisaram o desempenho no serviço de ténis sob o efeito de um constrangimento de tarefa e de ambiente. Mendes e colaboradores (2015) concluíram que uma perturbação extrínseca, vento lateral artificial, modificou a organização temporal mas sem comprometer a padrão cinético do movimento, ou seja, não provocou uma variabilidade extrema mas sim funcional na execução do serviço em jogadores peritos. Deste modo, os jogadores ao serem constrangidos por esta perturbação extrínseca, vento lateral artificial, autoorganizaram o seu sistema motor e fizeram emergir um comportamento compensatório no acréscimo de velocidade máxima na componente horizontal, isto com vista ao ajuste espaciotemporal da raquete aquando do impacto da bola. Isto acaba por ser relevante na medida em que Bernstein (1967), Davids e colegas (2008), Newell (1986), e Warren (1990) referem que as mudanças ambientais podem afetar significativamente os padrões de movimento já existentes. No caso concreto desta investigação, a monitorização de condições experimentais similares ao vento lateral a favor (i.e., da esquerda para a direita, em destrímanos) acarretou as alterações nos parâmetros de ação (velocidade e amplitude da raquete durante a execução do serviço) ao padrão do serviço em jogadores experientes.

Face ao exposto, o constrangimento extrínseco aqui apresentado é uma ferramenta útil para evitar o efeito de plateau na performance do serviço em jogadores peritos (Davids e col., 2008). Deste modo, os treinadores podem adotar como estratégia de melhoria da velocidade máxima do serviço a prática deste gesto, em condições de vento lateral, uma vez que permite ao jogador minimizar o efeito deste constrangimento, aumentando assim a velocidade máxima da raquete. Assim, como a dimensão horizontal da velocidade (eixo y) parece ser determinante para a velocidade pós-impacto do serviço (Tanabe \& Ito, 2007), a adoção desta abordagem pedagógica 
não-linear, a qual manipula e constrange as condições de envolvimento e da tarefa (Farrow \& Reid, 2010), pode igualmente influenciar a velocidade máxima de saída do serviço.

Em linha com o exposto, Menayo e colegas (2010) desenvolveram um programa de aprendizagem de 4 batimentos de ténis aplicando a variabilidade mediante a interferência contextual - prática aleatória e por bloco - com jogadores de nível intermédio. Neste estudo concluiu-se que a aplicação de variabilidade nos processos de aprendizagem deve realizar-se com 'cautela', e isto porque os resultados mostraram que, tanto a prática constante como a prática variável podem ser benéficas para a aprendizagem. Fatores relacionados com a carga de variabilidade, como o tipo de tarefa ou habilidade motora a aprender e os efeitos de interferência de habilidades motoras entre outros -, podem provocar uma variabilidade mais ou menos apropriada. Conclusões semelhantes foram obtidas por Menayo e colaboradores (2012), nos estudos realizados sobre o serviço de ténis, tendo concluído que uma quantidade de variabilidade excessiva aplicada como carga de aprendizagem, pode afetar negativamente a velocidade da bola e da precisão alcançada em cada batimento.

Deste modo, cabe ressalvar a importância de ajustar a carga de variabilidade como constrangimento associado à tarefa de aprendizagem das habilidades motoras e dos batimentos de ténis. A forma de realizar o referido ajuste deve sustentar-se na análise cinemática e cinética de cada batimento quando se aplica uma perturbação e os efeitos que esta produz nas variáveis de processo e de produto. Neste sentido, Moreno e Ordoño (2015) afirmam que a carga de prática variável deveria modelar-se em função das características da tarefa a aprender e dos objetivos de rendimento. Os mesmos autores consideram ainda que a variabilidade deve realizar-se não unicamente na magnitude mais adequada, mas igualmente no contexto da variação onde se produz a adaptação desejada. Por outro lado, se a prática em condições de variabilidade se afastar dos parâmetros comuns 
da tarefa pode provocar adaptações indesejadas. Face ao descrito, e em linha com Menayo e Fuentes (2011), a prática variável não deve afastar-se excessivamente do próprio padrão de movimento, sob pena de uma transferência negativa sobre a técnica, o que prejudicaria o rendimento. Neste sentido, o treinador deve indagar acerca da idoneidade da carga de variabilidade a prescrever nas execuções, devendo o processo de aprendizagem produzir destabilizações desequilíbrios - nos atratores existentes no sistema formado pelo tenista, pela tarefa e pelo contexto. No plano prático, tal desiderato é possível: realizando serviços com elevação da bola desde uma posição frontal ou desde uma posição de desequilíbrio mediante apoio unipedal; variando as distâncias do serviço relativamente à rede ou aos ângulos relativos à área de serviço e; modificando a superfície de apoio. Assim, estas perturbações procuram gerar um novo estado a partir da autorganização dos componentes do referido sistema na presença de ruído, podendo, uma vez que houve um aumento da complexidade da tarefa, reencontrar as cadeias de movimento que permitam a máxima eficácia dos batimentos.

Partindo destas premissas, e conforme recomendam Menayo e Fuentes (2011), o treinador pode utilizar diversas estratégias para o desenho das tarefas e sua aplicação em court:

1. Provocar perturbações que afetem a orientação espacial, as distâncias, as velocidades e acelerações, as amplitudes do movimento e os tempos de execução.

2. Alterar o meio, utilizando diferentes materiais e instrumentos.

3. Modificar as superfícies de apoio - praticar em água ou areia, adotar posições com diferentes estabilidades, entre outras.

A variabilidade funcional, ao ser entendida como parte integrante, omnipresente e inevitável no comportamento motor (Davids e col., 2003), deve assumir um papel central no processo de treino. 


\section{Bibliografia}

Adams, J.A. (1971). A closed-loop theory of motor learning. Journal of Motor Behaviour, 2, 111-150.

Araújo, D. (2005). A acção táctica no desporto uma perspectiva geral. In D. Araújo (Ed.), O Contexto da Decisão - A Acção Táctica no Desporto (pp. 21-33). Lisboa: Visão e Contextos.

Araújo, D. (2006). Tomada de Decisão no Desporto. Cruz Quebrada: Edições FMH.

Araújo D. \& Carvalho, J. (2007). Tomada de decisão no ténis. In P. Pezarat-Correia, C. Coutinho (Eds.), Investigação e Ténis (pp. 85-102). Cruz Quebrada: Edições FMH.

Arutyunyan, G.H., Gurfinkel, V.S., \& Mirskii, M.L. (1968). Investigation of aiming at a target. Biophysics, 13, 536-538.

Bartlett, R., Wheat, J., \& Robins, M. (2007). Is movement variability important for sports biomechanists? Sports Biomechanics, 6, 224-243.

Bernstein, N. (1967). The Coordination and Regulation of Movements. Oxford: Pergamon.

Blázquez, D., \& Hernández, J. (1984). Clasificación o Taxonomías Deportivas (Monografía). Barcelona: INEF.

Bootsma, R.J., \& van Wieringen, P.W.C. (1990). Timing an attacking forehand drive in table tennis. Journal of Experimental Psychology: Human Perception and Performance, 16, 21-29.

Castejón, F. (1995). Fundamentos de Iniciación Deportiva y Actividades Físicas Organizadas. Madrid: Dykinson.

Crespo, M. (2009). Tennis coaching in the era of dynamic systems. Journal of Medicine and Science in Tennis, 14, 20-25.

Davids, K., \& Araújo, D. (2005). A abordagem baseada nos constrangimentos para o treino desportivo. In D. Araújo (Ed.), o Contexto da Decisão - A Acção Táctica no Desporto (pp. 35-60). Lisboa: Edições Visão e Contextos.

Davids, K., Bennett, S.J., Handford, C., \& Jones, B. (1999). Acquiring coordination in selfpaced extrinsic timing tasks: A constraints led perspective. International journal of Sport Psychology, 30, 437-61.

Davids, K., Button, C., \& Bennett, S.J. (2008). Dynamics of Skill Acquisition - A ConstraintsLed Approach. Champaign, IL: Human Kinetics.

Davids, K., Glazier, P., Araújo, D., \& Bartlett, R. (2003). Movement systems as dynamical systems: the functional role of variability and its implications for sports medicine. Sports Medicine: Reviews of Applied Medicine and Science in Sport and Exercise, 33, 245-260.

Davids, K., Savelsbergh, G.J.P., \& Miyahara, M. (2010). Identifying constraints on children with movement difficulties. Implications for pedagogues and clinicians. In I. Renshaw, K. Davids, G.J.P. Savelsbergh (Eds.), Motor Learning in Practice (pp. 173-186). London: Routledge.

Elliott, B., Reid, M., \& Crespo, M. (2009). Technique development in tennis stroke production. London: International Tennis Federation.

Farrow, D., \& Reid, M. (2010). Skill acquisition in tennis.Equipping learners for success. In I. Renshaw, K. Davids, G.J.P. Savelsbergh (Eds.), Motor Learning in Practice. A ConstraintsLed Approach (pp. 231-240). London: Routledge. 
Gibson, J. (1966). The Senses Considered as Perceptual Systems. Boston: Houghton Mifflin.

Gibson, J. (1979). The Ecological Approach to Visual Perception. Hillsdale, NJ: Lawrence Erlbaum Associates.

Girard, O., Micallef, J., \& Millet, G. (2007). Influence of restricted knee motion during the flat first serve in tennis. The Journal of Strength and Conditioning Research, 21, 950-957.

Glazier, P.S., \& Davids, K. (2009). Constraints on the complete optimization of human motion. Sports Medicine, 39, 15-28.

Goodman, D., \& Kelso, J.A.S. (1980). Are movements prepared in parts? Not under compatible (naturalized) conditions. Journal of Experimental Psychology: General, 109, 475-495.

Gorospe, G., Hernández, A., Teresa, M., \& Martínez, R. (2005). Desarrollo y optimización de una herramienta observacional en el ténis de individuales. Psicotbema, 17, 123-127.

Hamill, J., Haddad, J.M., Heiderscheit, B.C., Van Emmerik, R.E.A., \& Li, Li (2006). Clinical relevance of variability in coordination. In K. Davids, S. Bennett, K. Newell (Eds.), Movement System Variability (pp. 153-165). Champaign, IL: Human Kinetics.

Handford, C. (2006). Serving up variability and stability. In K. Davids, S. Bennett, K. Newell (Eds.), Movement System Variability (pp 73-83). Champaign, IL: Human Kinetics.

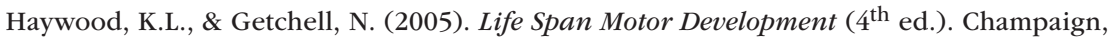
IL: Human Kinetics.

Hernández, J. (1994). Fundamentos del deporte. Análisis de las Estructuras del Juego Deportivo. Barcelona: INDE.

Hernández, J. (2005). Fundamentos del deporte. Análisis de las Estructuras del Juego Deportivo. Barcelona: INDE.

Hughes, O.M., \& Abbs, J.H. (1976). Labialmandibular coordination in the production of speech: implications for the operation of motor equivalence. Phonetica, 44, 199-221.

Kudo, K., \& Ohtsuki, T. (2008). Adaptive variability in skilled human movements. Japanese Society for Artificial Intelligence, 23,151-162.

Latash, M.L., Scholz, J.P., \& Schöner, G. (2002). Motor control strategies revealed in the structure of motor variability. Exercise and Sport Sciences Reviews, 30, 26-31.

Menayo, R. (2010). Análisis de la relación entre la consistencia en la ejecución del patrón motor del servicio en tennis, la precisión y su aprendizaje en condiciones de variabilidad (Doctoral Thesis). Universidad de Extremadura, Cáceres.

Mendes, P.C., Couceiro, M., Rocha, R., Clemente, F., Martins, F.L.M., Mendes, R., \& Fuentes, J.P. (2015). Effects of an Extrinsic Constraint on the Tennis Serve. International Journal of Sports Science and Coaching. DOI: http://dx.doi. org/10.1260/1747-9541.10.1.97.

Mendes, P.C., Dias, G., Mendes, R., Martins, F.M.L., Couceiro, M.S., \& Araújo, D. (2012). The effect of artificial side wind on the serve of competitive tennis players. International Journal of Performance Analysis in Sport, 3, 546-562.

Mendes, P.C., Fuentes, J.P., Mendes, R., Martins, F.M.L., Clemente, F., \& Couceiro, M.S. (2013). The variability of the serve toss in tennis under the influence of artificial crosswind. Journal of Sports Science and Medicine, 12, 309-315. 
Moreno, F.J., Gutierrez, O., \& Urban, T. (2011). Throwing variability and accuracy under instability conditions in young team-handeball players. In: NT Cable, $\mathrm{K}$ George (eds) $16^{\circ}$ European College of Sport Science (p. 326). European College of Sport Science, Liverpool.

Newell, K.M. (1986). Constraints on the development of coordination. In: M.G. Wade, H.T.A. Whiting (ed) Motor Development in children: Aspects of coordination and control (pp. 341-360). Martinus Nijhoff, Boston.

Newell, K.M., \& Corcos, D.M. (1993). Issues in variability and motor control. In: K.M. Newell, D.M. Corcos (eds) Variability and motor control (pp. 1-12). Human Kinetics Publishers, Champaign, IL.

Newell, K.M., \& Jordan, K. (2007). Task constraints and movement organization: a common language. In: W.E. Davids, G.D. Broadhead (eds) Ecological task analysis and movement (pp. 5-23). Human Kinetics, Champaign, IL.

Newell, K.M., \& Ranganathan, R. (2010). Instructions as constraints in motor skill acquisition. In: I. Renshaw, K. Davids, G.J.P. Savelsbergh (eds), Motor Learning in practice (pp. 17-32). Routledge, New York.

Newell, K.M., \& Villancourt, D. (2001). Dimensional change in motor learning. Human Movement Science,14-15, 695-716.

Parlebas, P. (1981). Contribution à un lexique commenté en science de l'action motrice. INSEP, Paris.

Pellegrini, A.M. (2001). Percepção-Acção e Controle Motor no Estudo do Comportamento Motor. Motriz, 7, S49-S56.

Reid, M., Whiteside, D., \& Elliott, B. (2010). Effect of skill decomposition on racket and ball kinematics of the elite junior tennis serve. Sports Biomechanics, 9, 296-303.

Riley, M. A., \& Turvey, M.T. (2002). Variability and determinism in motor behaviour. Journal of Motor Behaviour, 34, 99-125.

Schmidt, R.A. (1975). A schema theory of discrete motor skill learning. Psychological Review, 82, 225-260.

Schöllhorn, W.I. (1999). Individualität-ein vernachlässsigter parameter? Leistungtsport, 29, 4-11.

Scholz, J.P., Schöner, G., \& Latash, M.L. (2000). Motor control of pistol shooting: Identifying control variables with the uncontrolled manifold. Experimental Brain Research, 135, 382-404.

Tanabe, S., Ito, A. (2007). A three-dimensional analysis of the contributions of upper limb joint movements to horizontal racket head velocity at ball impact during tennis serving. Sports Biomechanics, 6, 418-433.

Tani, G. (1998). Aprendizagem motora: tendências, perspectivas e problemas de investigação. Revista Galelo-Portuguesa de Psicoloxía e Educación, 2, 1138-1663.

Tani, G. (2005). Comportamento motor. Aprendizagem e desenvolvimento. Guanabara Koogan, Rio de Janeiro.

Warren, W.H. (1990). The perception-Action Coupling. In: H. Bloch, B.I. Bertenthal (eds) Sensory-motor Organizations and development in Infancy and Early Childhood (pp.23-37). Kluwer Academic Publishers, Dordecht. 